\title{
15 A \\ Total Synthesis and Revision of the Antidiabetic Activity of (-)-Tarchonanthuslactone
}

\author{
Luiz F. T. Novaes, Carolina M. Avila, Gabriela F. P. de Souza, Lucas F. R. do \\ Nascimento, Licio A. Velloso, Ronaldo A. Pilli* \\ Institute of Chemistry, UNICAMP, Campinas-SP, Brazil \\ *e-mail corresponding author: pilli@iqm.unicamp.br
}

Keywords: Diabetes, (-)-tarchonanthuslactone, caffeic acid

\section{INTRODUCTION}

(-)-Tarchonanthuslactone (1) was isolated from the leaves of Tarchonanthus trilobus in $1979,{ }^{1}$ but a through study about its biological profile is still lacking. In 2000, Hsu and coworkers reported the antidiabetic effect of caffeic acid (2) in rats which contains the pharmacophoric group catechol, also present in 1. After that, several reports in the literature ${ }^{3}$ wrongly assigned antidiabetic effect to 1 making reference to the work of Hsu and coworkers. Since we detected this mistake, we decided to synthesize $(-)-(\mathbf{1})$ via a catalytic enantioselective synthesis as well as a key analogue and their possible products of hydrolysis, to analyze their effect on diabetic mice.

\section{RESULTS AND DISCUSSION}

Our approach began with the reduction of the natural polymer PHB (3), protection with TBS group, selective removal of the primary TBS, and oxidation of the corresponding primary alcohol. Aldehyde 4 was then submitted to a catalytic asymmetric allylation reaction (d.r. 93:7), esterification with acryloyl chloride, ring closing metathesis reaction with Grubbs' catalyst I and deprotection with HF•pyr (Scheme 1).

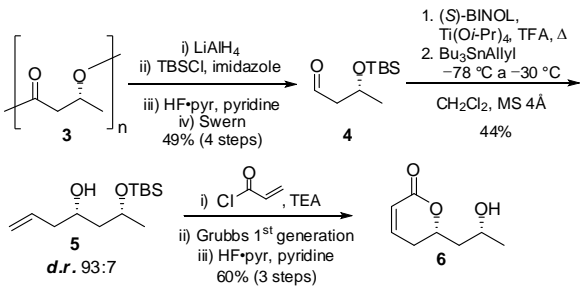

Scheme 1. Synthesis of intermediate 6

The side chain of the natural product (1) and analogue (10), and the dihydrocaffeic acid (9) were prepared from the commercial caffeic acid (2) (Scheme 2).

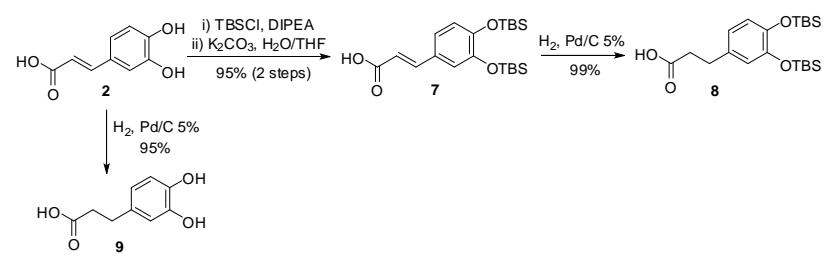

Scheme 2. Synthesis of acids 7-9.
After some tests, the best condition to esterification of $\mathbf{6}$ was achieved with $\mathrm{EDC} \cdot \mathrm{HCl}$ (Scheme $\mathbf{3}$ ).

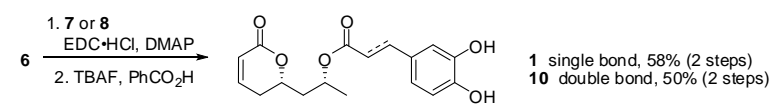

Scheme 3. Synthesis of (-)-tarchonanthuslactone (1) and analogue 10.

The first biological assays were performed with diabetic mice (Figure 1). Caffeic acid (2) as well as its saturated derivative $\mathbf{9}$ displayed reduction of glucose in the blood, in accordance with the results by $\mathrm{Hsu}$ and coworkers $^{3}$, while lactone 6 was ineffective. To our surprise, (-)-tarchonanthuslactone (1) and its analogue (10) promoted an increase in the glucose level in the blood.

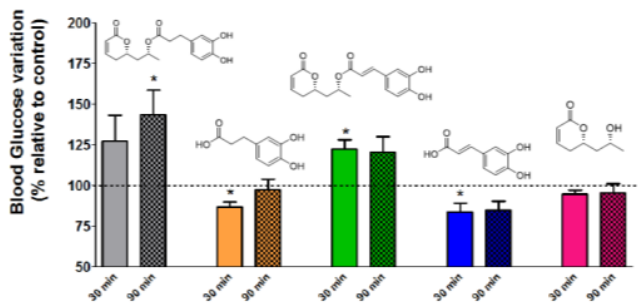

Figure 1. Effect of (-)-tarchonanthuslactone (1) and related compounds in diabetic mice.

\section{CONCLUSION}

We have developed a new synthesis of (-)tarchonanthuslactone (1) based on a catalytic asymmetric allylation which displayed opposite effect in diabetic mice in contrast to the activity reported for caffeic acid. Additionally, this work corrects wrong information in the literature about the antidiabetic effect of $\mathbf{1}$. The mechanism of action is currently under investigation.

\section{ACKNOWLEDGEMENTS}

The authors thank FAPESP for the financial support (proc. 2012/09254-2), and the Institute of Chemistry and Medical Faculty of Unicamp for the structure.

\section{REFERENCES}

${ }^{1}$ Bohlmann, F.; Suwita, A. Phytochemistry. 1979, 18, 677-678.

2 Hsu, F. L., et al. Planta Med. 2000, 66, 228-230.

${ }^{3}$ a) Lee, H. Y.; Sampath, V.; Yoon, Y. Synlett. 2009, 2, 249-252. b) George, S., Sudalai, A.Tetrahedron-Asymmetr. 2007, 18, 975-981. c) Yadav, J. S. et al. Tetrahedron. 2007, 63, 2689-2694. d) Baktharaman, S., et al. Tetrahedron Lett. 2005, 46, 7527-7529. e) Scott, M. S., Luckhurst, C. A., Dixon, D. J. Org. Lett. 2005, 7, 5813-5816. f) Enders, D., Steinbusch, D. Eur. J. Org. Chem. 2003, 2003, 4450-4454. g) Garaas, S. D., et al. J. Org. Chem. 2002. 67, 2682-2685. 